\title{
Effects of frailty and chronic diseases on quality of life in Dutch community-dwelling older adults: a cross-sectional study
}

This article was published in the following Dove Press journal:

Clinical Interventions in Aging

\author{
Inge Renne' \\ Robbert JJ Gobbens ${ }^{2-4}$ \\ 'General Practice Beeker, Hofland \\ Medisch Centrum, Mijdrecht, the \\ Netherlands; ${ }^{2}$ Faculty of Health, \\ Sports and Social Work, Inholland \\ University of Applied Sciences, \\ Amsterdam, the Netherlands; \\ ${ }^{3}$ Zonnehuisgroep Amstelland, \\ Amstelveen, the Netherlands; \\ ${ }^{4}$ Department of General Practice, \\ University of Antwerp, Antwerp, \\ Belgium
}

Objective: The aim of this cross-sectional study was to determine the associations between frailty and multimorbidity on the one hand and quality of life on the other in communitydwelling older people.

Methods: A questionnaire was sent to all people aged 70 years and older belonging to a general practice in the Netherlands; 241 persons completed the questionnaire (response rate $47.5 \%$ ). For determining multimorbidity, nine chronic diseases were examined by self-report. Frailty was assessed by the Tilburg Frailty Indicator, and quality of life was assessed by the World Health Organization Quality of Life Instrument-Older Adults Module.

Results: Multimorbidity, physical, psychological, as well as social frailty components were negatively associated with quality of life. Multimorbidity and all 15 frailty components together explained $11.6 \%$ and $36.5 \%$ of the variance of the score on quality of life, respectively.

Conclusion: Health care professionals should focus their interventions on the physical, psychological, and social domains of human functioning. Interprofessional cooperation between health care professionals and welfare professionals seems necessary to be able to meet the needs of frail older people.

Keywords: older people, frailty, quality of life, multimorbidity

\section{Introduction}

It is estimated that by $205033.2 \%$ of the population in the Netherlands will be aged 60 years and older. ${ }^{1}$ Frailty is considered one of the most complex and important issues associated with human aging, which has significant implications for the patient and the health care system. ${ }^{2}$ The relationship between frailty and a higher risk of falling, loss of functional independence, reduced quality of life, institutionalization, and mortality is clearly demonstrated..$^{3-8}$

There are two different approaches to the assessment of frailty: one defines frailty as a physical phenotype ${ }^{2}$ and the other considers frailty more as a multidimensional concept, which not only refers to physical functioning, but also to psychological and social functioning. These two different approaches are also reflected in the instruments that have been developed for assessing frailty. The phenotype of frailty is a good example of the first approach. ${ }^{2}$ Examples of instruments based on a multidimensional approach to frailty are: the Groningen Frailty Indicator, ${ }^{9}$ the Frailty Index, ${ }^{10}$ EASY-Care Two step Older people Screening, ${ }^{11}$ and the Tilburg Frailty Indicator (TFI). ${ }^{12}$ Recently, a systematic review concluded that the latter instrument has the most evidence of reliability and validity of 38 frailty assessment instruments. ${ }^{13}$
Correspondence: Robbert JJ Gobbens Faculty of Health, Sports and Social Work, Inholland University of Applied Sciences, De Boelelaan I 109, 108I HV Amsterdam, the Netherlands Tel +3 I 621 II 5578

Email robbert.gobbens@inholland.nl (c) (1) (2) 2018 Renne and Gobbens. This work is published and licensed by Dove Medical Press Limited. The full terms of this license are available at https://www.dovepress.com/terms.php
and incorporate the Creative Commons Attribution - Non Commercial (unported, v3.0) License (http://creativecommons.org/licenses/by-nc/3.0/). By accessing the work you (c)
hereby accept the Terms. Non-commercial uses of the work are permitted without any further permission from Dove Medical Press Limited, provided the work is properly attributed. For permission for commercial use of this work, please see paragraphs 4.2 and 5 of our Terms (https://www.dovepress.com/terms.php).
her 
In addition to frailty, the number of Dutch people with chronic diseases is also increasing. Almost half of the total population has at least one chronic disease; this concerns 8.2 million people in the Netherlands. ${ }^{14}$ Among the most common chronic diseases in this population are arthritis, diabetes mellitus, heart disease, cancer, and stroke. Multimorbidity, having two or more chronic diseases at the same time, is present in more than two-thirds of Dutch people aged 65 years or older. ${ }^{15}$ Multimorbidity is associated with hospital admissions, emergency department visits, and a reduction in quality of life. ${ }^{16-22}$ It is also known that multimorbidity is more common in women than men.

Previous studies have shown that both frailty and multimorbidity are associated with lower quality of life in older people. ${ }^{6,23-28}$ Quality of life is defined by the World Health Organization (WHO) as "an individual's perception of their own position in life in the context of the culture and value systems in which they live and in relation to their goals, expectations, standards and concerns" (p. 1405). ${ }^{29}$ Most of these studies have used the World Health Organization Quality of Life Instrument (WHOQOL-BREF) or the 36-Item Short Form Survey (SF-36) to assess quality of life. . $^{624,25,30-32}$ However, the WHOQOL-BREF and the SF-36 are not particularly developed for assessing quality of life in older people. Recently, the World Health Organization Quality of Life Instrument - Older Adults Module (WHOQOL-OLD), an instrument containing specific quality of life facets important for older people (eg, items related to death and dying), ${ }^{33}$ has been validated among Dutch older people and its psychometric properties were satisfactory. ${ }^{34}$

Dutch policy is aimed at older people staying in their own home, living independently, even if they are frail and multimorbidity is present. The general practitioner has a central role in identifying complex problems in older people. In consultation with other health care professionals, interventions should be planned and carried out so older people have the possibility to continue to live at home and admission to a nursing home is prevented or delayed. However, a general practitioner does not always know which of their patients are frail; in particular, psychological and social problems (eg loneliness) relating to psychological and social frailty are not always known, and their major impact on quality of life has been shown in previous studies. ${ }^{24,31}$

The aim of this study was to determine the associations between frailty and multimorbidity on the one hand and quality of life assessed with the WHOQOL-OLD on the other in community-dwelling older people linked to a general practice. It should be noted that our study has similarities with a previous study; ${ }^{35}$ in both studies, frailty and quality of life were measured with the TFI and the WHOQOL-OLD, respectively. Also, both studies included a sample of Dutch community-dwelling older people aged 70 years or older. However, there are some differences between the two studies. In our study the sample contained people connected to one general practice, versus people distributed throughout the Netherlands in the previous study. In addition, multimorbidity was assessed by adding up the presence of nine chronic diseases instead of one question, and the number of participants was lower (241 vs 466). Nevertheless, it offers a unique opportunity to compare and to discuss in detail the results of both studies in the last section.

\section{Methods \\ Design}

A cross-sectional design was used.

\section{Study population and data collection}

In October 2016 a questionnaire was sent to all people aged 70 years and older belonging to a general practice situated in an area of small villages close to Amsterdam, the capital of the Netherlands. In total, 507 people aged 70 years and older were contacted, of whom 241 completed the questionnaire (response rate $47.5 \%$ ).

\section{Measures}

Frailty

Frailty was assessed by Part B of the TFI, a user-friendly self-report questionnaire. ${ }^{12}$ Part B consists of 15 components of frailty, subdivided into three domains: physical (eight components, range 0-8 points), psychological (four components, range 0-4 points), and social (three items, range $0-3$ points). Table 1 presents these 15 components of frailty. The maximum score for total frailty is 15 points. Higher scores correspond to a more serious frailty status; scores $\geq 5$ indicate that the assessed individual is frail. The TFI has shown good psychometric properties in Dutch community-dwelling older people. ${ }^{12,36}$ In the present study, the reliability expressed by Cronbach's alpha for frailty total and the physical, psychological, and social domains is 0.80 , $0.74,0.61$, and 0.51 , respectively.

\section{Quality of life}

Quality of life was assessed by the WHOQOL-OLD. ${ }^{33}$ This questionnaire is derived from the WHOQOL-100 and is 
Table I Participant characteristics $(\mathrm{N}=24 \mathrm{I})$, regarding sociodemographic characteristics, chronic diseases, and quality of life

\begin{tabular}{|c|c|}
\hline Characteristic & n (\%) \\
\hline \multicolumn{2}{|l|}{ Sociodemographic characteristics } \\
\hline Age, mean (SD), range & 76.5 (5.I), 70-90 \\
\hline Sex (men) & $125(51.9)$ \\
\hline \multicolumn{2}{|l|}{ Marital status } \\
\hline Married or cohabiting & $|7|(7 \mid)$ \\
\hline Divorced & $5(2.1)$ \\
\hline Not married & II (4.6) \\
\hline Widowed & $54(22.4)$ \\
\hline \multicolumn{2}{|l|}{ Education } \\
\hline None or primary & $54(22.4)$ \\
\hline Secondary & I 44 (59.8) \\
\hline Higher & $43(17.8)$ \\
\hline \multicolumn{2}{|l|}{ Chronic diseases } \\
\hline Number of chronic diseases, mean (SD), range & I.I (I.I), 0-5 \\
\hline Diabetes mellitus & $48(19.9)$ \\
\hline COPD & $26(10.8)$ \\
\hline Cardiac disease & $58(24.1)$ \\
\hline Arthrosis & $96(39.8)$ \\
\hline Cerebrovascular accidents & $6(2.5)$ \\
\hline Cancer & $25(10.4)$ \\
\hline Dementia & $4(1.7)$ \\
\hline Depression & $7(2.9)$ \\
\hline Parkinson's disease & $6(2.5)$ \\
\hline Multimorbidity & $73(30.3)$ \\
\hline \multicolumn{2}{|l|}{ Frailty } \\
\hline Total frailty, mean (SD), range & $3.4(3.1), 0-13$ \\
\hline Physical domain, mean (SD), range & $1.9(2.0), 0-7$ \\
\hline Physically unhealthy & $40(16.6)$ \\
\hline Unexplained weight loss & $18(7.5)$ \\
\hline Difficulty in walking & $86(35.7)$ \\
\hline Difficulty in maintaining balance & $60(24.9)$ \\
\hline Poor hearing & $67(27.8)$ \\
\hline Poor vision & $42(17.4)$ \\
\hline Lack of strength in the hands & $62(25.7)$ \\
\hline Physical tiredness & $76(31.5)$ \\
\hline Psychological domain, mean (SD), range & 0.7 (I.0), 0-4 \\
\hline Problems with memory & II (4.6) \\
\hline Feeling down & $74(30.7)$ \\
\hline Feeling nervous or anxious & $52(21.6)$ \\
\hline Unable to cope with problems & $34(28.6)$ \\
\hline Social domain, mean (SD), range & $0.8(0.9), 0-3$ \\
\hline Living alone & $69(28.6)$ \\
\hline Lack of social relations & $95(39.4)$ \\
\hline Lack of social support & $27(I I .2)$ \\
\hline \multicolumn{2}{|l|}{ Quality of life, mean (SD), range } \\
\hline Total quality of life & 92.2 (10.9), 59-119 \\
\hline Sensory abilities & 16.4 (2.9), 7-20 \\
\hline Autonomy & I4.8 (2.6), 5-20 \\
\hline Past, present, and future activities & I5.4 (2.4), 8-20 \\
\hline Social participation & I $5.4(2.8), 5-20$ \\
\hline Death and dying & 14.9 (2.9), 5-20 \\
\hline Intimacy & I5.3 (2.6), 5-20 \\
\hline
\end{tabular}

specifically developed to measure quality of life in older people. It consists of 24 items being equally distributed over six facets: sensory abilities; autonomy; past, present, and future abilities; social participation; death and dying; and intimacy. Reponses were rated on a 5-point Likert scale (1-5), with higher scores indicating better quality of life. Facet and total scores range from 4 to 20 and from 24 to 120 points, respectively. In this study, Cronbach's alpha values for quality of life total and the facets of sensory abilities, autonomy, past, present, and future abilities, social participation, death and dying, and intimacy were $0.89,0.82,0.70,0.78,0.86$, 0.79 , and 0.87 , respectively.

\section{Chronic diseases}

Nine chronic diseases, frequently present in the older Dutch population, were examined by self-report: diabetes mellitus, COPD, cardiac disease, arthrosis, cerebrovascular accident, cancer, dementia, depression, and Parkinson's disease. The total number of chronic diseases was used for analysis concerning multimorbidity.

\section{Sociodemographic characteristics}

The sociodemographic characteristics considered were age, sex, marital status, and highest education attained. See Table 1 for a detailed description of the response categories.

\section{Statistical analyses}

First, we determined the characteristics of the participants using descriptive statistics. Second, the quality of life facet scores and total scores for nonfrail and frail participants were compared using Student's $t$-tests assuming unequal population variances. Effect size was assessed with Cohen's $d(0.2$, 0.5 , and 0.8 corresponding to small, medium, and large effect size, respectively), ${ }^{37}$ assuming equal population variances. Then, we determined the correlations between frailty total, the three domains of frailty (physical, psychological, and social), multimorbidity, and the six quality of life facets and quality of life total. Finally, we used sequential multiple linear regression analyses for assessing the effect of the individual frailty components of the TFI and multimorbidity on the seven quality of life variables of the WHOQOL-OLD. These analyses consisted of three blocks; the first block contained the sociodemographic characteristics of the participants, the second block contained multimorbidity, and the third block contained the 15 frailty components. The second and third blocks enabled testing the effect of multimorbidity and the individual frailty components on quality of life variables, 
respectively, after controlling for all the other variables in the model.

For statistical analyses, we used IBM SPSS Statistics 22.0 (IBM Corporation, Armonk, NY, USA). $p<0.05$ was considered statistically significant.

\section{Ethical considerations}

The study was conducted according to the ethical guidelines laid down in the Declaration of Helsinki. Medical ethics approval was not necessary as particular treatments or interventions were not offered or withheld from respondents as a consequence of participating in the study, this being the main criterion in medical-ethical procedures in the Netherlands according to the Medical Research Involving Subjects Act (WMO). ${ }^{38}$ In addition, the integrity of respondents was not encroached upon as a consequence of participating in the study and the actual burden of completing the questionnaire was very low. Nevertheless, written informed consent for the collection and use of information was obtained from all participants.

\section{Results}

\section{Participant characteristics}

The mean age of the participants was 76.5 years (SD 5.1; range $70-90)$. In total, 51.9\% were men, 71\% were married or cohabiting, and most of them had secondary education level (59.8\%). Arthrosis was the most common chronic disease $(39.8 \%)$. The mean TFI total score was 3.4 (SD 3.1 ) and the mean WHOQOL-OLD total score was 92.2 (SD 10.9). The prevalence of frailty in the sample was $32.8 \%$. Of the individual frailty components, lack of social relations referring to feelings of loneliness had the highest prevalence $(39.4 \%)$ and problems with memory had the lowest prevalence $(4.6 \%)$. Multimorbidity was present for $30.3 \%$ of the participants. Detailed information is presented in Table 1.

\section{Differences between nonfrail and frail participants on quality of life facets and total}

Table 2 presents the results of the $t$-tests aimed at testing the differences in the scores of the nonfrail group and the frail group on quality of life facets and quality of life total of the WHOQOL-OLD. Frail participants scored lower on all quality of life variables (all $p<0.001$ ), with effect sizes varying from 0.50 (death and dying) to 1.56 (quality of life total).

\section{Correlations between frailty domains, multimorbidity, and quality of life facets and total}

All negative correlations between frailty domains and the six quality of life facets and quality of life total were significant (see Table 3). Of the quality of life facets, both physical and psychological frailty had the strongest correlations with social participation ( -0.528 and -0.519 , respectively); social frailty had the strongest correlation with intimacy $(-0.562)$. Multimorbidity was significantly negatively correlated with five out of six quality of life facets and quality of life total. Multimorbidity had the strongest correlation with social participation (-0.381), and was only not correlated with the quality of life facet death and dying $(-0.118)$, although the sign of the effect was as expected.

\section{Sequential multiple linear regression analyses}

Table 4 presents the results of the sequential multiple linear regression analyses, showing one model with all of the variables included. The rows $\Delta R^{2}$ indicate how much of the variance in the quality of life scores (facets, total) was explained by the variables belonging to the three blocks (background characteristics, multimorbidity, frailty components), and whether (the increase in) explained variance was statistically significant. The second block containing multimorbidity

Table 2 Comparison of quality of life between frail and nonfrail participants

\begin{tabular}{|c|c|c|c|c|}
\hline & $\begin{array}{l}\text { Nonfrail } \\
n=162, \\
\text { mean (SD) }\end{array}$ & $\begin{array}{l}\text { Frail } \\
\mathrm{n}=79, \\
\text { mean (SD) }\end{array}$ & Results of Student $t$-test ${ }^{a}$ & $\begin{array}{l}\text { Effect size } \\
\text { Cohen's d }\end{array}$ \\
\hline Sensory abilities & $17.22(2.57)$ & $14.82(2.81)$ & $t(143.07)=6.39, p<0.001$ & 0.90 \\
\hline Autonomy & $|5.4|(2.4 \mid)$ & $13.48(2.43)$ & $t(153.79)=5.82, p<0.001$ & 0.80 \\
\hline Past, present, and future activities & $16.24(1.87)$ & |3.6| (2.26) & $t(|3| .48)=8.97, p<0.00 \mid$ & 1.31 \\
\hline Social participation & $16.42(2.05)$ & $13.37(2.96)$ & $t(I \mid 5.80)=8.24, p<0.00 I$ & 1.28 \\
\hline Death and dying & $15.36(2.73)$ & $13.96(2.98)$ & $t(143.35)=3.52, p<0.001$ & 0.50 \\
\hline Intimacy & $16.07(2.15)$ & I 3.75 (2.78) & $t(124.63)=6.54, p<0.001$ & 0.98 \\
\hline Total quality of life & $96.73(8.32)$ & $82.99(9.67)$ & $t(136.00)=10.83, p<0.001$ & 1.56 \\
\hline
\end{tabular}

Notes: a Assuming unequal population variances. ${ }^{b}$ Assuming equal population variances. 
Table 3 Correlations between frailty domains, multimorbidity, and quality of life facets and total

\begin{tabular}{|c|c|c|c|c|c|c|c|}
\hline & $\begin{array}{l}\text { Sensory } \\
\text { abilities }\end{array}$ & Autonomy & $\begin{array}{l}\text { Past, present, and } \\
\text { future activities }\end{array}$ & $\begin{array}{l}\text { Social } \\
\text { participation }\end{array}$ & $\begin{array}{l}\text { Death } \\
\text { and dying }\end{array}$ & Intimacy & Total \\
\hline Frailty total & $-0.442 * * *$ & $-0.435 * * *$ & $-0.589 * * *$ & $-0.60 I^{* * *}$ & $-0.257^{* * *}$ & $-0.480 * * *$ & $-0.684 * * *$ \\
\hline Frailty physical & $-0.462 * * *$ & $-0.403 * * *$ & $-0.50 \mathrm{I} * * *$ & $-0.528 * * *$ & $-0.188 * *$ & $-0.33 \mathrm{I} * * *$ & $-0.589 * * *$ \\
\hline Frailty psychological & $-0.289 * * *$ & $-0.352^{* * *}$ & $-0.485^{* * *}$ & $-0.519 * * *$ & $-0.257^{* * *}$ & $-0.328 * * *$ & $-0.544 * * *$ \\
\hline Frailty social & $-0.189 * *$ & $-0.223 * * *$ & $-0.391 * * *$ & $-0.335^{* * *}$ & $-0.189 * *$ & $-0.562 * * *$ & $-0.457 * * *$ \\
\hline Multimorbidity & $-0.316 * * *$ & $-0.257^{* * *}$ & $-0.319 * * *$ & $-0.38 \mathrm{I} * * *$ & -0.118 & $-0.162 *$ & $-0.381 * * *$ \\
\hline
\end{tabular}

Notes: $* p<0.05 ; * * p<0.01 ; * * *<<0.001$.

explained a significant part of five quality of life facets and quality of life total, ranging from $2.5 \%$ (intimacy) to $12.0 \%$ (social participation), after controlling for the background characteristics and the frailty components; the exception was quality of life facet death and dying. The third block containing the 15 frailty components explained a significant part of all quality of life facets and total, ranging from $4.5 \%$ (death and dying) to $36.5 \%$ (total quality of life), after controlling for the variables of the first and second block. The last row $\left(R^{2}\right.$ total) shows that all of the predictors together explained $17.8 \%$ of quality of life facet death and dying to $55.6 \%$ of quality of life total.

Of the 15 frailty components, the physical frailty components physically unhealthy, difficulty in walking, and poor hearing were negatively associated with at least two quality of life variables. The components feeling down and unable to cope with problems relating to psychological frailty were negatively associated with three and four quality of life variables, respectively. These were the only predictors of quality of life facet death and dying. Finally, the social frailty components lack of social relations and lack of social support were negatively associated with five and three quality of life variables, respectively. These two frailty components were the only predictors of quality of life facet intimacy.

\section{Discussion}

This study showed that multimorbidity as well as frailty were associated with quality of life total, measured with the WHOQOL-OLD in Dutch community-dwelling older people aged 70 years and older related to a general practice. In addition, multimorbidity and the total of the individual physical, psychological, and social frailty components of the TFI were associated with five and all six quality of life facets of the WHOQOL-OLD, respectively.

The finding that multimorbidity was associated with lower quality of life in older people is confirmed by many other quantitative studies, as mentioned in the Introduction, ${ }^{18-21}$ independent of the amount of the included chronic diseases, ranging from $14^{17}$ to 45 conditions..$^{20}$ Only a study by
Yamada et $\mathrm{l}^{39}$ used the WHOQOL-OLD for assessing quality of life. This study concluded that the negative impact of the existence of multiple conditions on quality of life might be mitigated by promoting a positive self-perception of aging in older people..$^{39}$ Duguay et al ${ }^{40}$ suggest that inquiring about what multimorbidity means to older adults might be an efficient method for nurses and other health care professionals in primary care settings to assess coping processes and enhance the relationships between the health care professionals and the older individual with multimorbidity.

The finding that frailty was associated with lower quality of life is also supported by other studies. Previous studies have shown that frail older people experience a lower quality of life, regardless of how both frailty and quality of life are measured, eg phenotype of frailty and the SF-36, ${ }^{6,25,30,32}$ or the TFI and the WHOQOL-BREF. ${ }^{24,31}$ Both studies using the TFI and WHOQOL-BREF were conducted in the Netherlands. The first study demonstrated that the prediction of all quality of life domains (physical health, psychological, social relations, environmental) by eight physical frailty components was improved after adding four psychological and three social frailty components; only the frailty component feeling down predicted all four quality of life domains. ${ }^{24}$ The second study showed that the frailty components difficulty in maintaining balance, physical tiredness, physical unhealthy, difficulty in walking, feeling down, and lack of social support predicted future scores on the domains of the WHOQOL-BREF. ${ }^{31}$ The latter four components predicted in our study at least two quality of life variables.

Only one previous study has used the same instruments for measuring frailty and quality of life as we did, the TFI and the WHOQOL-OLD, respectively. ${ }^{35}$ Therefore, as mentioned in the Introduction, we will compare our findings regarding the associations between frailty and quality of life in particular with this previous study. In most cases, the correlations between the three frailty domains and the six quality of life facets were stronger in our study. This is especially true for the correlations between physical, psychological, and social frailty and the quality of life facets autonomy and 


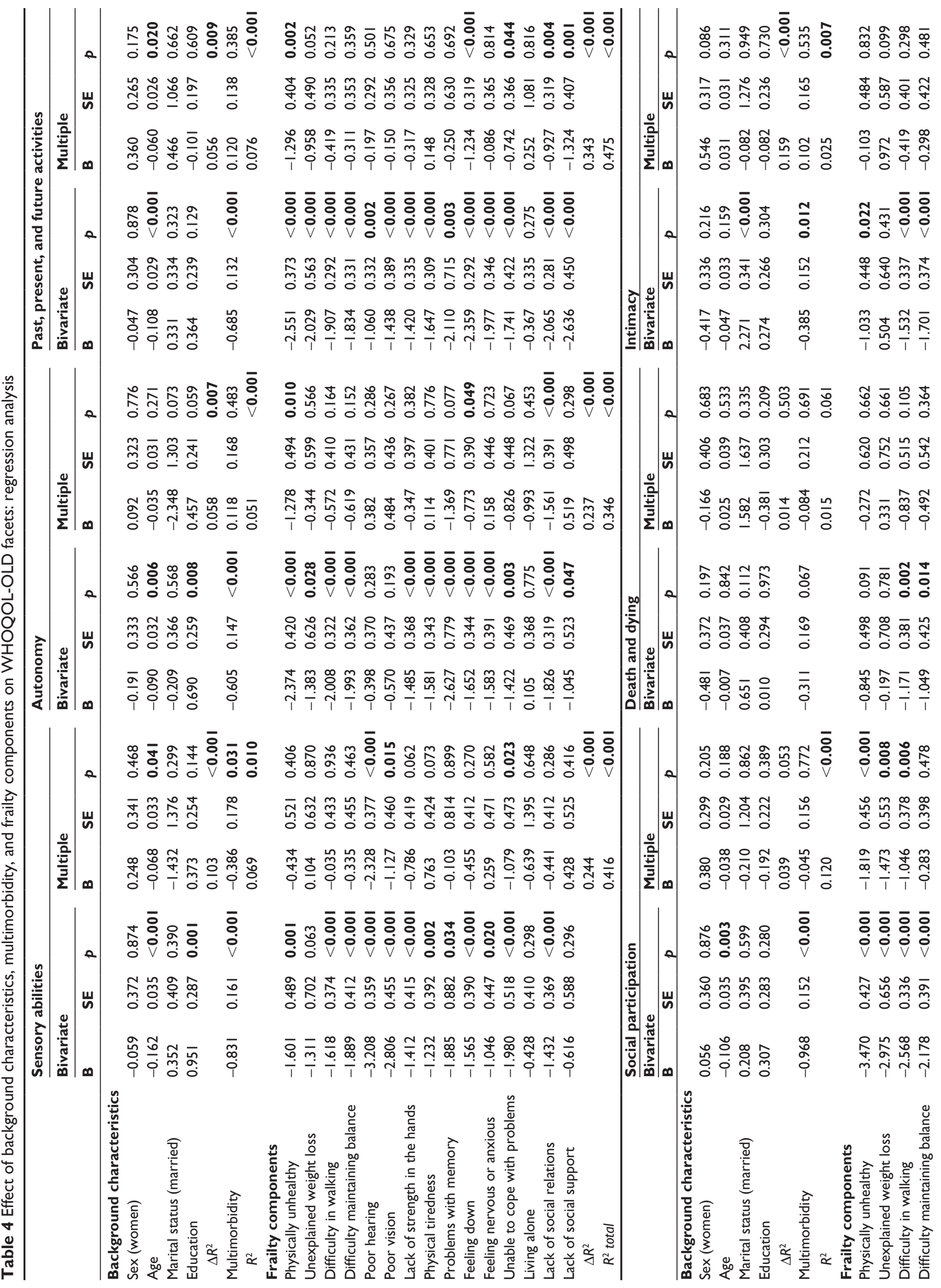




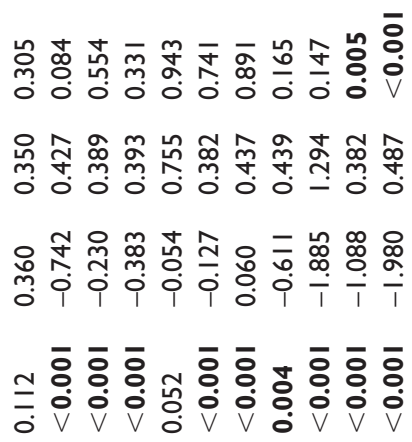

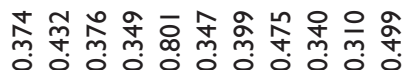

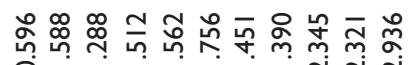

i门广

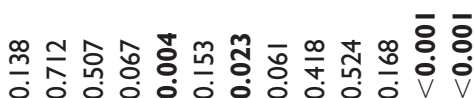

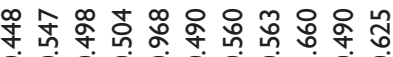

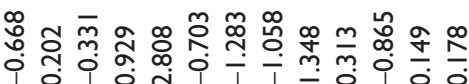

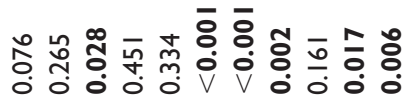

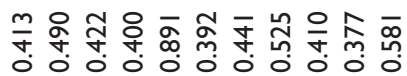

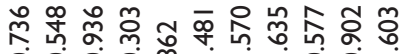

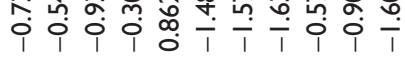

๓

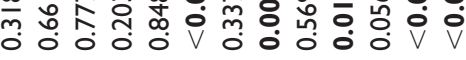

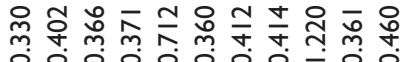

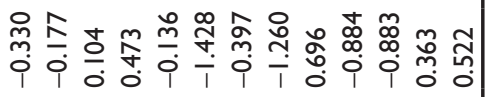

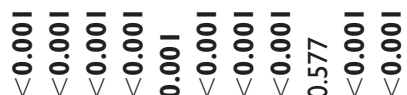

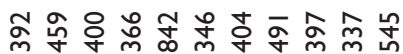

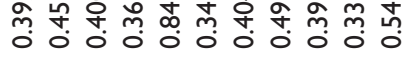

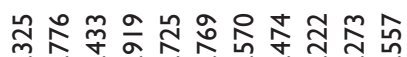

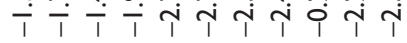

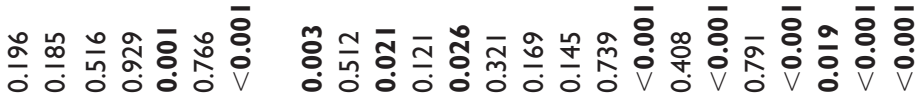

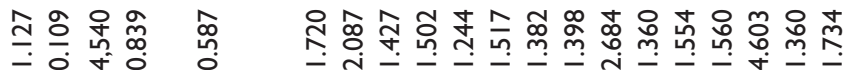

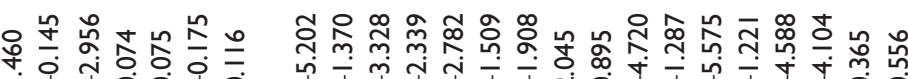

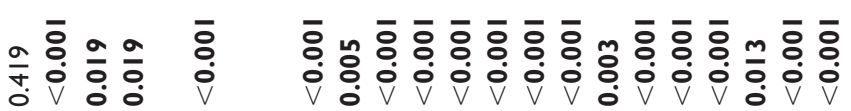

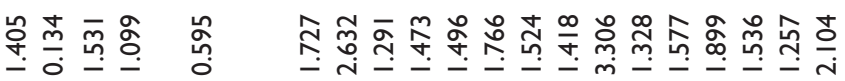

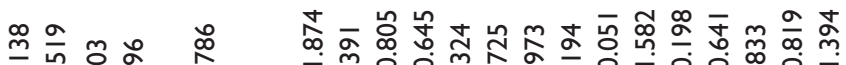

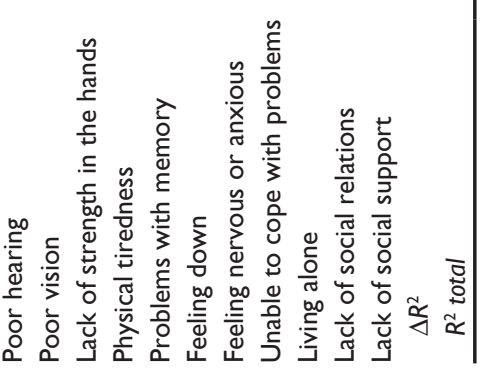

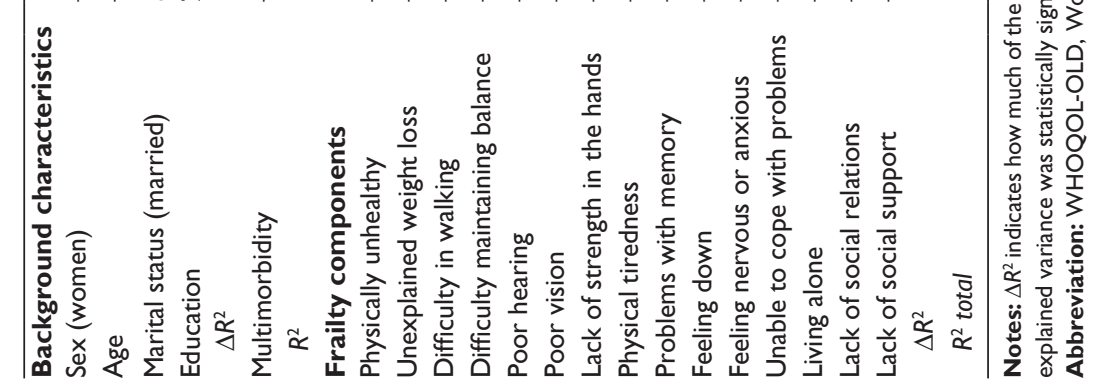


past, present, and future activities. Most striking is that we found an association between social frailty and quality of life autonomy and the previous study found no association. A possible explanation for these differences in findings may be found in the characteristics of the samples. In our sample the percentage of men was $51.9 \%$, vs $69.4 \%$ in the other study. The sequential regression analyses in the previous study showed that being a woman was positively associated with autonomy; that was not the case in the current study. In addition, the average score on social frailty was lower ( 0.8 vs 0.95 ); our analyses showed that in our study fewer people had a lack of social relations (feelings of loneliness), $39.4 \%$ vs $53.1 \%$.

The 15 frailty components together explained 36.5\% of the variance of the score on quality of life total; this percentage was higher comparable with the previous study $(31.8 \%) .{ }^{35}$ This also applies for the explained variances of the scores on five of the six quality of life facets. The differences in explained variances range from 5.1\% (death and dying) to $1.2 \%$ (social participation). The exception is quality of life facet sensory abilities, for which the explained variances were $24.4 \%$ and $43.4 \%$ for the current and previous study, respectively. Our findings are remarkable because the number in our study is lower (241 vs 466), so the study by Gobbens and van Assen ${ }^{35}$ had more power and could more easily find effects of frailty on quality of life. An explanation for our findings should also be sought in differences in the samples. Differences not only exist in sex, but also in level of education; in the present study $40.9 \%$ were highly educated, while this percentage was $17.8 \%$ in the previous study. ${ }^{35}$ In the latter study, a Web-based questionnaire was used for collecting the data. As the authors have indicated, using this questionnaire has probably led to selection bias.

The scores on three quality of life facets (autonomy, past, present, and future activities, social participation) were explained by components belonging to physical, psychological, and social frailty. Scores on sensory abilities were only explained by physical and psychological frailty components. Scores on quality of life facet death and dying were only explained by psychological frailty components and scores on quality of life facet intimacy were only explained by social frailty components. Similar to other studies, our study underlines the importance of a multidimensional assessment of frailty aiming to explain quality of life in older adults. ${ }^{24,31}$ In particular, our study shows that social frailty, which is too often ignored in definitions of frailty, eg the phenotype of frailty, ${ }^{2}$ is essential in explaining quality of life.
This study has several limitations to mention. First, the effect of the frailty components on quality of life facet sensory abilities is influenced by the overlap between two physical frailty components, poor hearing and poor vision, and the four items of this WHOQOL-OLD facet. Second, we used a cross-sectional design for determining the effect of frailty on quality of life; because of this design, strict causeeffect interpretations are not possible. Third, the sample is not representative; $51.9 \%$ of the participants were men, while in the Dutch population aged 70 years and older only $43.5 \%$ are men. ${ }^{41}$ Moreover, in our sample $71 \%$ of the participants were married or cohabiting and $11.4 \%$ were widowed, versus percentages of $55.2 \%$ and $31.4 \%$, respectively, for the Dutch population. ${ }^{41}$ These differences in percentages can be explained by the fact that no people older than 90 years participated in our study.

\section{Conclusion}

Multimorbidity and frailty were negatively associated with quality of life in community-dwelling older people. Our findings regarding frailty, measured with the TFI, a multidimensional frailty questionnaire, have many similarities with the findings in the previous study by Gobbens and van Assen. ${ }^{35}$ In both studies, physical, psychological, as well as social frailty components were negatively associated with quality of life. This means that health care professionals should focus their interventions on all three domains of human functioning (physical, psychological, and social). According to the present study, health care professionals should in particular pay attention to physically unhealthy, lack of social relations, lack of social support, feeling down, and unable to cope with problems because these frailty components have the biggest impact on quality of life in older people. Interprofessional cooperation between health care professionals and welfare professionals seems necessary to be able to meet the needs of frail older people. This cooperation should lead to a tailor-made plan for each individual, which is not only focused on deficits, but also on the strengths and resources that older people may have.

\section{Acknowledgments}

The authors would like to thank Marcel ALM van Assen, $\mathrm{PhD}$, for his methodological and statistical support and Jaco A Beeker, MD, for making it possible to conduct the study from his general practice.

\section{Disclosure}

The authors report no conflicts of interest in this work. 


\section{References}

1. United Nations Department of Economic and Social Affairs. Population Division. World Population Prospects. The 2015 Revision. Key Findings and Advance Tables. Working Paper No. ESA/P/WP.241. New York: United Nations; 2015. Available from: http://esa.un.org/ unpd/wpp/publications/files/key_findings_wpp_2015.pdf. Accessed July 19, 2017.

2. Fried LP, Tangen CM, Walston J, et al. Frailty in older adults: evidence for a phenotype. J Gerontol A Biol Sci Med Sci. 2001;56(3):M146-M156.

3. Ensrud KE, Ewing SK, Taylor BC, et al. Frailty and risk of falls, fracture, and mortality in older women: the study of osteoporotic fractures. J Gerontol A Biol Sci Med Sci. 2007;62(7):744-751.

4. Al Snih S, Graham JE, Ray LA, Samper-Ternent R, Markides KS, Ottenbacher KJ. Frailty and incidence of activities of daily living disability among older Mexican Americans. J Rehabil Med. 2009;41(11): 892-897.

5. Boyd CM, Xue QL, Simpson CF, Guralnik JM, Fried LP. Frailty, hospitalization, and progression of disability in a cohort of disabled older women. Am J Med. 2005;118(11):1225-1231.

6. Chang YW, Chen WL, Lin FG, et al. Frailty and its impact on healthrelated quality of life: a cross-sectional study on elder community-dwelling preventive health service users. PloS One. 2012;7(5):e38079.

7. Puts MT, Lips P, Deeg DJ. Sex differences in the risk of frailty for mortality independent of disability and chronic diseases. J Am Geriatr Soc. 2005;53(1):40-47.

8. Gale CR, Cooper C, Deary IJ, Aihie Sayer A. Psychological well-being and incident frailty in men and women: the English Longitudinal Study of Ageing. Psychol Med. 2014;44(4):697-706.

9. Schuurmans H, Steverink N, Lindenberg S, Frieswijk N, Slaets JPJ. Old or frail: what tells us more? J Gerontol A Biol Sci Med Sci. 2004;59(9): M962-M965.

10. Mitnitski AB, Mogilner AJ, Rockwood K. Accumulation of deficits as a proxy measure of aging. ScientificWorldJournal. 2001;1:323-336.

11. van Kempen JA, Schers HJ, Jacobs A, et al. Development of an instrument for the identification of frail older people as a target population for integrated care. Br J Gen Pract. 2013;63(608):e225-e231.

12. Gobbens RJ, van Assen MA, Luijkx KG, Wijnen-Sponselee MT, Schols JM. The Tilburg Frailty Indicator: psychometric properties. J Am Med Dir Assoc. 2010;11(5):344-355.

13. Sutton JL, Gould RL, Daley S, et al. Psychometric properties of multicomponent tools designed to assess frailty in older adults: a systematic review. BMC Geriatr. 2016;16(1):55.

14. NIVEL. Zorgregistraties eerste lijn. Available from: https:// www.volksgezondheidenzorg.info/onderwerp/chronische-ziektenen-multimorbiditeit/cijfers-context/prevalentie\#node-prevalentiechronische-ziekte-naar-leeftijd-en-geslacht. Accessed July 19, 2017.

15. NIVEL. Zorgregistraties eerste lijn. Available from: https://www. volksgezondheidenzorg.info/onderwerp/chronische-ziekten-enmultimorbiditeit/cijfers-context/prevalentie\#node-prevalentiemultimorbiditeit-naar-leeftijd-en-geslacht. Accessed July 19, 2017.

16. van den Bussche H, Schön G, Kolonko T, et al. Patterns of ambulatory medical care utilization in elderly patients with special reference to chronic diseases and multimorbidity - Results from a claims data based observational study in Germany. BMC Geriatr. 2011;11:54.

17. Fortin M, Bravo G, Hudon C, et al. Relationship between multimorbidity and health-related quality of life of patients in primary care. Qual Life Res. 2006;15(1):83-91.

18. Agborsangaya CB, LauD, Lahtinen M, Cooke T, JohnsonJA. Health-related quality of life and healthcare utilization in multimorbidity: results of a cross-sectional survey. Qual Life Res. 2013;22(4):791-799.

19. Barile JP, Thompson WW, Zack MM, Krahn GL, Horner-Johnson W, Bowen SE. Multiple chronic medical conditions and health-related quality of life in older adults, 2004-2006. Prev Chronic Dis. 2013;10:E162.
20. Brettschneider C, Leicht H, Bickel H, et al. Relative impact of multimorbid chronic conditions on health-related quality of life - results from the MultiCare Cohort Study. PloS One. 2013;8(6):e66742.

21. Garin N, Olaya B, Moneta MV, et al. Impact of multimorbidity on disability and quality of life in the Spanish older population. PloS One. 2014;9(11):e111498.

22. Mujica-Mota RE, Roberts M, Abel G, et al. Common patterns of morbidity and multi-morbidity and their impact on health-related quality of life: evidence from a national survey. Qual Life Res. 2015;24(4):909-918.

23. Bilotta $\mathrm{C}$, Bowling $\mathrm{A}$, Casè $\mathrm{A}$, et al. Dimensions and correlates of quality of life according to frailty status: a cross-sectional study on community-dwelling older adults referred to an outpatient geriatric service in Italy. Health Qual Life Outcomes. 2010;8:56.

24. Gobbens RJ, Luijkx KG, van Assen MA. Explaining quality of life of older people in the Netherlands using a multidimensional assessment of frailty. Qual Life Res. 2013;22(8):2051-2061.

25. Lin CC, Li CI, Chang CK, et al. Reduced health-related quality of life in elders with frailty: a cross-sectional study of community-dwelling elders in Taiwan. PloS One. 2011;6(7):e21841.

26. Masel MC, Graham JE, Reistetter TA, Markides KS, Ottenbacher KJ. Frailty and health related quality of life in older Mexican Americans. Health Qual Life Outcomes. 2009;7:70.

27. Fortin M, Lapointe L, Hudon C, Vanasse A, Ntetu AL, Maltais D. Multimorbidity and quality of life in primary care: a systematic review. Health Qual Life Outcomes. 2004;2:51.

28. Nobrega TC, Jaluul O, Machado AN, Paschoal SM, Jacob Filho W. Quality of life and multimorbidity of elderly outpatients. Clinics (Sao Paulo, Brazil). 2009;64(1):45-50.

29. The WHOQOL Group. The World Health Organization Quality of Life assessment (WHOQOL): position paper from the World Health Organization. Soc Sci Med. 1995;41(10):1403-1409.

30. Masel MC, Ostir GV, Ottenbacher KJ. Frailty, mortality, and health-related quality of life in older Mexican Americans. J Am Geriatr Soc. 2010; 58(11):2149-2153.

31. Gobbens RJ, van Assen MA. The prediction of quality of life by physical, psychological and social components of frailty in communitydwelling older people. Qual Life Res. 2014;23(8):2289-2300.

32. Mulasso A, Roppolo M, Rabaglietti E. The role of individual characteristics and physical frailty on health related quality of life (HRQOL): a cross sectional study of Italian community-dwelling older adults. Arch Gerontol Geriatr. 2014;59(3):542-548.

33. Power M, Quinn K, Schmidt S; WHOQOL-OLD Group. Development of the WHOQOL-old module. Qual Life Res. 2005;14(10):2197-2214.

34. Gobbens RJ, van Assen MALM. Psychometric properties of the Dutch WHOQOL-OLD. Health Qual Life Outcomes. 2016;14(1):103.

35. Gobbens RJJ, van Assen MALM. Associations between multidimensional frailty and quality of life among Dutch older people. Arch Gerontol Geriatr. 2017;73:69-76.

36. Gobbens RJ, van Assen MA, Luijkx KG, Schols JM. The predictive validity of the Tilburg Frailty Indicator: disability, health care utilization, and quality of life in a population at risk. Gerontologist. 2012;52(5): 619-631.

37. Cohen J. Statistical Power Analysis for the Behavioral Sciences. 2nd ed. Hillsdale, NJ, USA: Lawrence Erlbaum Assoc; 1988.

38. Central Committee on Research Involving Human Subjects. Your Research: Does it Fall Under the WMO. Available from: http://www.ccmo.nl/en/ your-research-does-it-fall-under-the-wmo. Accessed June 20, 2016.

39. Yamada Y, Merz L, Kisvetrova H. Quality of life and comorbidity among older home care clients: role of positive attitudes toward aging. Qual Life Res. 2015;24(7):1661-1667.

40. Duguay C, Gallagher F, Fortin M. The experience of adults with multimorbidity: a qualitative study. J Comorb. 2014;4:11-21.

41. Statistics Netherlands. StatLine [database on the Internet]. Available from: http://statline.cbs.nl/StatWeb/. Accessed July 19, 2017. 


\section{Publish your work in this journal}

Clinical Interventions in Aging is an international, peer-reviewed journal focusing on evidence-based reports on the value or lack thereof of treatments intended to prevent or delay the onset of maladaptive correlates of aging in human beings. This journal is indexed on PubMed Central, MedLine,

CAS, Scopus and the Elsevier Bibliographic databases. The manuscript management system is completely online and includes a very quick and fair peer-review system, which is all easy to use. Visit http://www.dovepress. com/testimonials.php to read real quotes from published authors.

Submit your manuscript here: http://www.dovepress.com/clinical-interventions-in-aging-journal 